\title{
Kinetic study of the microwave-induced thermal degradation of cv. Arbequina olive oils flavored with lemon verbena essential oil
}

\author{
Marwa Cherif $^{1}$ | Nuno Rodrigues ${ }^{1}$ | Ana C. A. Veloso ${ }^{2,3}$ | \\ José Alberto Pereira ${ }^{1}$ (ㅇ) | António M. Peres ${ }^{1}$ (
}

${ }^{1}$ Centro de Investigação de Montanha (CIMO), Instituto Politécnico de Bragança, Campus de Santa Apolónia, Bragança, Portugal

${ }^{2}$ Instituto Politécnico de Coimbra, ISEC, DEQB, Rua Pedro Nunes, Quinta da Nora, Coimbra, Portugal

${ }^{3} \mathrm{CEB}$ - Centre of Biological Engineering, University of Minho, Campus de Gualtar, Braga, Portugal

\section{Correspondence}

António M. Peres, Centro de Investigação de Montanha (CIMO), Instituto Politécnico de Bragança, Campus de Santa Apolónia, 5300-253 Bragança, Portugal.

Email: peres@ipb.pt

\section{Funding information}

European Regional Development Fund:

Project "GreenHealth", Grant/Award Number: (Norte-01-0145-FEDER-000042);

BioTecNorte operation, Grant/Award Number: (NORTE-01-0145-FEDER-000004);

Fundação para a Ciência e a Tecnologia, Grant/Award Numbers: CEB

(UIDB/04469/2020), CIMO (UIDB/00690/ 2020)

\begin{abstract}
The effect of typical domestic microwave heating $(0-15 \mathrm{~min}$, at $800 \mathrm{~W})$ on the thermal degradation of unflavored and flavored olive oils' minor bioactive compounds and related antioxidant activity was studied. Olive oils from cv. Arbequina were flavored with lemon verbena essential oil $(0 \%, 0.2 \%$ and $0.4 \%$, w/w) leading to a linear increase of total phenols $\left(112-160 \mathrm{mg}\right.$ gallic acid $\mathrm{kg}^{-1}$ oil, $R$-Pearson $=+0.9870)$, total carotenoids $\left(2.19-2.56 \mathrm{mg}\right.$ lutein $\mathrm{kg}^{-1}$ oil, $R$-Pearson $=+0.9611)$, and, to a less extent, of chlorophyll (2.32-3.19 mg pheophytin $\mathrm{kg}^{-1}$ oil, $R$-Pearson $=+0.8238$ ). However, no such linear trend was observed for the oxidative stability $(6.5-7.8 \mathrm{~h})$ or the radical scavenging activity (inhibition rates: $40 \%-43 \%$ ). The contents of total phenols, total carotenoids, and chlorophyll decreased with the rise of the microwave heating time, following their thermal degradation, a second-order kinetic model $(0.8784 \leq R$-Pearson $\leq 0.9926)$. The essential oil addition did not influence the estimated second-order rate reaction constants of total phenols $\left(0.00070-0.00072 \mathrm{~kg}\right.$ oil $\mathrm{min}^{-1} \mathrm{mg}^{-1}$ gallic acid)and total carotenoids (0.14- $0.17 \mathrm{~kg}$ oil $\mathrm{min}^{-1} \mathrm{mg}^{-1}$ lutein), with a broader variation observed for chlorophyll $\left(0.014-0.022 \mathrm{~kg}\right.$ oil $\mathrm{min}^{-1} \mathrm{mg}^{-1}$ pheophytin). Globally, total carotenoids degraded faster than total phenols and chlorophyll (half-life of 2.3-3.4, 8.8-12.8, and 14.5-30.8 min, respectively). Moreover, except for chlorophyll, the half-life of total phenols and carotenoids linearly decreased with the essential oil addition $(R-$ Pearson: -0.9999 and -0.9421 , respectively), showing that flavoring did not have a protective effect against degradation when subjected to a microwave heating.
\end{abstract}

\section{KEYWORDS}

bioactive compounds, degradation rate reaction constant, essential oil flavoring, half-life period, olive oil

\section{INTRODUCTION}

Olive oil (Olea europaea L.) is highly appreciated and a key element of the Mediterranean diet, being its intake associated to several health benefits mainly due to the rich composition of monounsaturated fatty acids and minor constituents like phenolic compounds and carotenoids (Emma et al., 2021; Pocovi-Gerardino et al., 2021). Olive oil is usually consumed as a raw product, in salads, or in foods after being adsorbed, when used as a cooking oil (Chiou \& Kalogeropoulos, 2017). As described in the literature, olive oil is resistant to oxidative deterioration when cooked (e.g., used as a frying oil), which is attributed to the high monounsaturated and low polyunsaturated fatty acid contents together with its composition in minor bioactive constituents that protect olive oil from extensive oxidative deterioration at high temperatures (Chiou \& Kalogeropoulos, 2017). However, several studies pointed out the negative impact of different heating processes (e.g., frying, baking, boiling, oven/conventional, and microwave heating) on the olive oil's chemical profile and composition (volatiles and phenolic compounds) as well as on the positive and appreciated sensory sensations (Jiménez et al., 2017; Prata et al., 2018). Still, olive 
oil is commonly used in both "healthy" (defined as habit of cooking meals with fresh and natural seasoning foods) and "convenience" (defined as less frequency and time to cook, using microwave and ready-to-heat meals) cooking patterns by worldwide consumers (Martins et al., 2021). Aiming to reduce the natural (due to storage) or accelerated (due to cooking) thermal degradation of olive oils as well as to meet sensory preferences of olive oil worldwide consumers, flavoring with aromatic herbs, spices, or essential oils (EO) has emerged as a commercial trend (Baiano et al., 2009; Caponio et al., 2016; Khemakhem et al., 2015). Several studies reported the kinetic modeling of bioactive compounds' degradation rates during thermal processing and/or storage, namely, for example, of saffron flowers and related bio-residues (Moratalla-López et al., 2019), common beans (Mba et al., 2019), Piper betle extracts (Ali et al., 2018), Brussels sprouts (Nakilcioglu-Taş \& Otleş, 2017), sea buckthorn (Ursache et al., 2017), plum extracts (Turturică et al., 2016), fresh fruit juices (Marszałek et al., 2015; Sapei \& Hwa, 2014), and apple peel by-products (Henríquez et al., 2014). Regarding olive oils, to the authors' best knowledge, only one study evaluated the thermal degradation kinetics of individual carotenoids (e.g., lutein, $\beta$-carotene and $\beta$-cryptoxanthin) of a blend virgin olive oil (cvs. Hojiblanca and Manzanilla) subjected to different time-temperature conditions (varying from $42 \mathrm{~h}$ at $120^{\circ} \mathrm{C}$ to $744 \mathrm{~h}$ at $60^{\circ} \mathrm{C}$ ) (Aparicio-Ruiz et al., 2011).

Thus, this study aims to evaluate the thermal degradation of cv. Arbequina oils, a worldwide widespread olive cultivar, during typical microwave heating process simulating a usual domestic use as well as the possible protective effect of oils' flavoring with lemon verbena EO (Aloysia citrodora) $(0 \%, 0.2 \%$ and $0.4 \%, w / w)$. This EO is recognized as one of the most valuable aromatic and medicinal plants with known positive health effects (Bahramsoltani et al., 2018; Combrinck et al., 2019). Recently, it was observed that flavoring cv. Arbequina oils with lemon verbena EO increased the antioxidant and total reducing capacities but decreased the oxidative stability (OS) (Cherif et al., 2021), and it was found that the oils' oxidation at high temperatures $\left(110-150^{\circ} \mathrm{C}\right)$ had a nonspontaneous, endothermic, and endergonic nature. In this sense, several parameters were evaluated namely the free acidity (FA), peroxide value (PV), extinction coefficients at 232 and $270 \mathrm{~nm}, K_{232}$ and $K_{270}$, as well as the radical scavenging antioxidant activity, total phenols content (TPC), total carotenoids content (TCC), and chlorophyll content. Besides, the degradation rates of the minor constituents (TPC, TCC, and chlorophyll) were also evaluated during the microwave heating at five usual domestic time periods $(0,1,3,5,10$, and $15 \mathrm{~min})$. For that, a kinetic approach was used, aiming, for the first time, to establish the half-life times of these compounds of unflavored and flavored $\mathrm{cv}$. Arbequina oils subjected to common microwave heating (cooking) patterns.

\section{MATERIALS AND METHODS}

\section{Olive oil samples and EO}

The cv. Arbequina extra virgin olive oils were produced from olives grown in an olive grove with high-density production mode located in Trás-os-Montes region. The olives were collected in 2019, and the oil was extracted in an olive mill (Olimontes) located in Macedo de Cavaleiros (Portugal), using a two-phase centrifugation system. The olive oils were kept in their original amber glass bottles (approximately $500 \mathrm{ml}$ ), during 4 months, in a dark environment, at room temperature $\left(18-25^{\circ} \mathrm{C}\right)$, and were filtrated before analysis. Then lemon verbena EO was added in different amounts allowing to obtain flavored oils with $0.2 \%$ and $0.4 \%(\mathrm{w} / \mathrm{w})$ of EO. In total, two independent closed amber glass bottles (with approximately $100 \mathrm{ml}$ of oil) were also stored in dark at $18-25^{\circ} \mathrm{C}$ during 2 weeks before being analyzed, for each flavoring concentration, plus other two bottles without no EO addition $(0.0 \%$, w/w), used as the control samples. Two weeks after being flavored, the oil from each independent bottle was analyzed in duplicate after being subjected to five microwave heating time-periods $(0,1,3,5,10$, and $15 \mathrm{~min}$, which corresponded to approximately, 20, 41, 115, 160, 205 , and $235^{\circ} \mathrm{C}$ ), at a preset power of $800 \mathrm{~W}$, using a microwave Amstrad (model WP810, London, UK), totalizing 60 assays for each evaluated parameter (i.e., 3 EO concentrations $\times 2$ independent bottles $\times 5$ heating time-periods $\times 2$ replicates $=60$ assays). Four quality parameters (FA, PV, and extinction coefficients at 232 and $270 \mathrm{~nm}$ ), the antioxidant activity, the OS at $120^{\circ} \mathrm{C}$, TPC, TCC, and chlorophyll content were assessed. The EO was purchased in a local specialty store devoted to the commercialization of EOs for the food industry. According to the label information, the EO had a lemony profile and sweet fresh aroma. All flavored oils could be easily recognized by nontrained consumers due to the perception of a lemony profile and sweet fresh taste/aroma (sensory attributes in accordance with the EO label). Lemon verbena EO was chosen due to its well-documented richness in polyphenols (Ishkeh et al., 2019; Rocha et al., 2019). The volatile composition of the lemon verbena EO was previously reported by Cherif et al. (2021) and was in line with the literature data, and no sign of deterioration was visible.

\section{Quality parameters and OS of unflavored and flavored olive oils}

The physicochemical quality parameters, the FA (in \% oleic acid), $\mathrm{PV}$ (in $\mathrm{mEq} \mathrm{O}_{2} / \mathrm{kg}$ ), and specific coefficients of extinction at $232 \mathrm{~nm}$ and $268 \mathrm{~nm}\left(K_{232}\right.$, and $\left.K_{268}\right)$ were evaluated according to the European Union 
Regulation (Commission Delegated Regulation [EU] 2015/1830, 2015). The OS (in h) was determined under accelerated oxidation conditions $\left(120^{\circ} \mathrm{C}\right)$ using the Rancimat method (Rancimat 743, Metrohm CH, Herisau, Switzerland) as previously described (Veloso et al., 2020). Briefly, $3 \mathrm{~g}$ of olive oil was heated at $120.0 \pm 1.6^{\circ} \mathrm{C}$ under a flow rate of $20 \mathrm{~L} / \mathrm{h}$ of air (filtered, cleaned, and dried), releasing volatile compounds that are collected in water, water conductivity $(\mathrm{mS} / \mathrm{cm})$ being continuously measured and plotted against time. The time (in hours) taken to reach the conductivity inflection curve point is determined, representing the OS of the oil.

\section{Chlorophyll and carotenoids contents of unflavored and flavored olive oils}

Chlorophyll and TCC were spectrophotometrically determined as previously described (MinguezMosquera et al., 1991). For the procedure, olive oil $(7.5 \mathrm{~g})$ was vortexed with cyclohexane (final volume of $25 \mathrm{ml}$ ) for $30 \mathrm{~s}$. After homogenization, the mixture was spectrophotometrically analyzed, at 470 and $670 \mathrm{~nm}$ for carotenoids and chlorophyll assessment, respectively. Chlorophyll content was expressed as $\mathrm{mg}$ of pheophytin equivalent per $\mathrm{kg}$ of oil and carotenoids contents as $\mathrm{mg}$ of lutein equivalent per $\mathrm{kg}$ of oil. The specific extinction coefficients considered for the calculation were 613 for pheophytin, as a major component of the chlorophyll fraction, and 2000 for lutein, as a major component of the carotenoid fraction. The pigments' contents were then calculated as follows (Equations (1) and (2)):

$$
\begin{gathered}
\text { Chlorophyll }\left(\frac{\text { mg pheophytin eq. }}{\text { kg oil }}\right)=\frac{A b s_{670} \times 10^{6}}{613 \times 100 \times d} \\
\text { Carotenoids }\left(\frac{\text { mglutein eq. }}{\text { kg oil }}\right)=\frac{A b s_{470} \times 10^{6}}{2000 \times 100 \times d}
\end{gathered}
$$

where $A b s$ is the absorbance at 670 or $470 \mathrm{~nm}$ and $d$ is the cuvette path length (equal to $1 \mathrm{~cm}$ ).

\section{TPC and antioxidant activity of unflavored and flavored olive oils}

TPC and the radical scavenging activity were assessed using olive oils' extracts obtained by micro methanolwater extraction (Pizarro et al., 2013). Briefly, in a 2 -ml Eppendorf tube, $1 \mathrm{ml}$ of methanol-water solution $(80 \%$ $\mathrm{MeOH}-\mathrm{H}_{2} \mathrm{O}, \mathrm{v} / \mathrm{v}$ ) was added to $0.5 \mathrm{~g}$ of olive oil. The mixture was vortexed for $1 \mathrm{~min}$ and then centrifuged during 5 min at 13,200 rpm (Minispin 5452 Eppendorf centrifuge). The supernatant (extract) was recovered into a 3-ml volumetric flask. The procedure was repeated twice, after the addition of $1 \mathrm{ml}$ of the $80 \% \mathrm{MeOH}-\mathrm{H}_{2} \mathrm{O}$ solution in the same Eppendorf centrifuge. The three extracts were collected and placed in the same 3-ml volumetric flask, which was then filled with ultrapure water. Each olive oil sample was extracted in triplicate.

For TPC assessment, $1.5 \mu \mathrm{l}$ of ultrapure water, $0.1 \mu \mathrm{l}$ of the phenolic extract, and $0.100 \mu \mathrm{l}$ of FolinCiocalteu reagent were vortexed for $3 \mathrm{~s}$ and allowed to react for $3 \mathrm{~min}$. After that, $0.300 \mu \mathrm{l}$ of $20 \%$ sodium carbonate $(\mathrm{w} / \mathrm{v})$ solution was added, vortexed for $3 \mathrm{~s}$, and further allowed to react for 60 min in the dark and at room temperature $\left(20-22^{\circ} \mathrm{C}\right)$. This procedure was carried out in triplicate, for each olive oil extract obtained according to the micro methanol-water extraction. All samples were spectrophotometrically evaluated (UVVIS/UV-1280 Shimadzu spectrophotometer) at $765 \mathrm{~nm}$. TPC quantification (in $\mathrm{mg}$ of gallic acid equivalents [GAE] per kg of oil) was carried out using a calibration curve between the absorbance and the GA concentration in methanol solution $\left(R^{2} \geq 0.9999\right)$.

The antioxidant capacity of olive oil samples was investigated and the radical scavenging activity (2,2-diphenyl-1-picrylhydrazyl) (DPPH) was assessed spectrophotometrically at $517 \mathrm{~nm}$ (UV-VIS/UV-1280 Shimadzu spectrophotometer), at $20^{\circ} \mathrm{C}$, using the extract solutions obtained according to the micro methanol-water extraction. The DPPH control solution was prepared by mixing $0.1 \mathrm{ml}$ of methanol and $3.9 \mathrm{ml}$ of DPPH $(0.06 \mathrm{mM})$, and the absorbance is being read after $30 \mathrm{~min}$ in the dark. Similarly, for the olive oil samples, $0.1 \mathrm{ml}$ of methanolic extract previously obtained was added to $3.9 \mathrm{ml}$ of DPPH $(0.06 \mathrm{mM})$, and the absorbance is being read after $30 \mathrm{~min}$ in the dark. The DPPH radical scavenging was expressed as the percentage of reduction of DPPH activity.

\section{Kinetic modeling of the thermal degradation reactions}

The observed changes on the contents of phenols, carotenoids, and chlorophyll (expressed in $\mathrm{mg} / \mathrm{kg}$ ) were used to calculate the thermal degradation reaction rates due to the microwave heating of unflavored and flavored olive oils. Three reaction orders were considered (zero-, first- and second-order kinetic models, Equation (3)), being selected the kinetic model that allowed the best mathematical fit of the experimental data for the thee oil types studied:

$$
-\frac{d C_{i}}{d t}=k \times C_{i}^{n}
$$

where $C_{i}$ is the content (in $\mathrm{mg} / \mathrm{kg}$ of oil) of the $i$ compound under analysis (TPC, TCC, or chlorophyll); $t$ is the microwave heating time-period (in $\mathrm{min}$ ); $k$ is the 
rate constant; and $n$ is the reaction order (equal to 0,1 , or 2 for zero-, first-, and second-order kinetic models, respectively).

The integration of the previous equation is straightforwardly assuming that $k$ is constant during the entire microwave heating time-period. Indeed, a pseudoconstant $k$ can be assumed, although the olive oil temperature increases during the heating time-period, as previously stated. Since a commercial home device was used to mimic the usual domestic microwave use, it is not possible to fix a constant temperature during the entire heating time-period, only being possible to fix the heating power, which turns out into an increasing heating temperature during the process. However, and as described in the literature, the microwave absorption is closely related to the moisture content of the samples under analysis and so, since the same sample weight $(m)$ was used in each assay and heating was conducted at a predefined and fixed microwave power $(P)$, the following equation can be used to describe the dependency of $k$ with $m, P$, and the energy of activation $\left(E_{\mathrm{a}}\right)$, based on the Arrhenius equation (Dadali et al., 2007; Demirhan \& Özbek, 2015; Kumar et al., 2019):

$$
k=k_{0} e^{\left(-\frac{E_{a}}{P / m}\right)}
$$

where $k_{0}$ is the pre-exponential constant.

Therefore, since $m$ and $P$ were the same in all assays, $k$ can be assumed as a constant allowing the usual integration of the empirical kinetic models (Equations (1)-(3)). This approach is in line with different researchers when studying the impact of the domestic microwave heating on the degradation kinetics of bioactive compounds of several food matrices (Dadali et al., 2007, 2009; Demirhan \& Özbek, 2009; Demirhan \& Özbek, 2015; Igoumenidis et al., 2011; Jaiswal \& AbuGhannam, 2013; Aamir \& Boonsupthip, 2017; Javidipour et al., 2017; Nakilcioglu-Taş \& Otleş, 2017; ilter et al., 2018; Kumar et al., 2019; Yarahmadi et al., 2020).

Thus, depending on the considered reaction order, for each parameter (TPC, TCC, or chlorophyll), three relationships (Equations (5)-(7)) can be established between the content and the heating time, after integrating Equation (3),

$$
\begin{aligned}
& \text { zero - order kinetic model }(n=0): C_{0}-C=k \times t \\
& \text { first - order kinetic model }(n=1): \ln \left(\frac{C_{0}}{C}\right)=k \times t \\
& \text { second - order kinetic model }(n=2): \frac{1}{C}-\frac{1}{C_{0}}=k \times t
\end{aligned}
$$

where $C_{0}$ is the content (in $\mathrm{mg} / \mathrm{kg}$ ) of TPC, TCC, or chlorophyll for the unheated olive oils (microwave heating time equal to 0 min for each flavored or not olive oil).

The linear regression in each case (i.e., $C_{0}-C$ vs. $t ; \ln \left(C_{0} / C\right)$ vs. $t$; or, $1 / C-1 / C_{0}$ vs. $t$, for the zero-, first-, or second-order kinetic model, respectively) would allow to estimate $k$, as the slope value of each regression, as well as the respective standard error (SE). It should be remarked that the units of $k$ depend on the model used, being $\mathrm{mg} / \mathrm{kg} \mathrm{min}^{-1} ; \mathrm{min}^{-1}$; and, $\mathrm{kg}$ $\mathrm{min}^{-1} \mathrm{mg}^{-1}$ for the zero-, first-, and second-order rate constants. Finally, half-life $\left(t_{1 / 2}\right.$, in min) of each compound, for unflavored and flavored olive oils, were estimated as the microwave heating time needed to decrease each content by $50 \%$ from its initial value $\left(C=0.5 \times C_{0}\right.$, in $\left.\mathrm{mg} / \mathrm{kg}\right)$, based on the previous kinetic models (Equations (5)-(7)), depending on the bestfitting model to the experimental data:

$$
\begin{gathered}
\text { zero - order kinetic model }(n=0): t_{1 / 2}=\frac{0.5 \times C_{0}}{k} \\
\text { first }- \text { order kinetic model }(n=1): t_{1 / 2}=\frac{\ln (2)}{k} \\
\text { second }- \text { order kinetic model }(n=2): t_{1 / 2}=\frac{1}{k \times C_{0}}
\end{gathered}
$$

\section{Statistical analysis}

Two-way analysis of variance (ANOVA) with interaction was applied to evaluate the statistical significance of olive oil flavoring, with lemon verbena EO $(0 \%, 0.2 \%$, and $0.4 \%, w / w)$ and microwave heating times $(0,1$, $3,5,10$, and $15 \mathrm{~min}$ ) on the cv. Arbequina oils' FA, peroxide value, extinction coefficients, OS, antioxidant activity, total phenols, total carotenoids, and chlorophyll contents. Depending on the statistical significance of the interaction effect and on the type of interaction found (additive or nonadditive/disordinal effect) post hoc multiple range tests or the estimated marginal mean plots were further used to discuss at which level the factors influenced the dependent variables under study (Field, 2009). Furthermore, a significant statistical interaction effect was assumed as additive if no crossing lines were observed on the estimated marginal mean plots representing the changes observed for both effects considered, for each of the parameters under study. The significance level was set at $5 \%$. The Pearson correlation coefficient ( $R$-Pearson) was calculated to infer about the existence of correlation trends of the oils' characteristics and the EO addition. Principal component analysis (PCA) was used, as an unsupervised multivariate pattern recognition technique, to further 
evaluate the type of oil-microwave heating times' differentiation capability based on the observed changes of the evaluated parameters. Linear regressions were also used to calculate the reaction rate constants of the thermal degradation of TPC, TCC, and chlorophyll content, which were performed after the linearization of the zero-, first-, and second-order kinetic models. The statistical analysis was performed using the subselect and MASS packages of the open-source statistical program R (version 3.6.2) (Cadima et al., 2004; Venables \& Ripley, 2002).

\section{RESULTS AND DISCUSSION}

\section{Impact of olive oil flavoring and microwave heating on the physicochemical and antioxidant characteristics of cv. Arbequina olive oils}

In this study, the possible protective impact of flavoring $\mathrm{cv}$. Arbequina olive oil was evaluated with different amounts of lemon verbena EO $(0.2 \%$ and $0.4 \%, w / w)$, on the oils' quality indices (FA, PV, $K_{232}$, and $K_{268}$ ), OS, antioxidant activity (DPPH), as well as on the TPC, TCC, and chlorophyll, against the thermal degradation during microwave heating $(0,1,3,5,10$, and $15 \mathrm{~min})$, by comparing with the observed behavior of unflavored oil ( $0 \%$ EO) under the same heating conditions. Table 1 shows the results according to each flavoring level and microwave heating time. Since two factors (flavoring and microwave heating) are being considered simultaneously, with possible interaction effects, a two-way ANOVA was performed. This analysis allowed, for each parameter studied, to determine the statistical significance of each main factor ("flavoring level" and "microwave heating") as well to verify if the interaction between the two main factors was significant or not. The results are shown in Table 2.

In which concerns the physicochemical quality parameters, the studied factors did not have a significant effect on the FA ( $p$-value $\geq 0.3700$; Table 2) and also no significant interaction effect was found ( $p$ value $=0.3780$; Table 2 ), demonstrating that cv. Arbequina oils' flavoring did not influence the FA, which was not affected by the different microwave heating times evaluated. These outcomes are in agreement with the previous findings of the research team (Cherif et al., 2021) and in line with the findings of Malheiro et al. (2009), Cerretani et al. (2009), and Yan et al. (2020). Recently, Kishimoto (2019) reported that the FA of olive oils was not affected by the microwave heating time, except when an intense microwave heating was applied (i.e., heating at $500 \mathrm{~W}$, reaching a temperature of $207^{\circ} \mathrm{C}$ ), which led to an FA increase over the heating procedure. On the other hand, Sevim et al. (2018) observed a slight increase of the FA of olive oils during microwave heating. In contrast, the microwave heating time had significant impact ( $p$-value $<0.0001$; Table 2 ) on all the other parameters (PV, $K_{232}, K_{268}, \mathrm{OS}, \mathrm{DPPH}$, TPC, TCC, and chlorophyll content) and the EO flavoring level only showed a significant effect on PV, $K_{232}, K_{268}$, TPC, and TCC ( $p$-value $\leq 0.0014$; Table 2 ), pointing out that the thermal degradation was mainly responsible for the observed changes and to a less extent, the flavoring level. The flavoring level did not had a clear effect on the OS, DPPH scavenging activity, TCC and chlorophyll amount, being higher values observed for heating times lower than 5 min. Lastly, higher TPC could be found for higher flavoring levels as well as after lower heating time-periods. These findings should be considered with precaution since, for the abovementioned five parameters, nonadditive significant interaction effects were found ( $p$ value $\leq 0.0117$; Table 2). For the PV, the results showed a slight decreasing trend with the increase of the flavoring level allowing to admit that the addition of the EO could have a protective effect against the olive oils' oxidative degradation and rancid formation, minimizing the reaction with free oxygen. This trend was contrary to that previously observed by Cherif et al. (2021) for cv. Arbequina also flavored with lemon verbena EO or in other studies (Baiano et al., 2009; Caponio et al., 2016), but similar to the trends reported by other researchers (Bobiano et al., 2019; Tarchoune et al., 2019) for different flavoring agents (e.g., fruits, leaves, dry or fresh spices, EO, or aromatic herbs). No obvious effect could be found regarding the microwave heating impact on the PV of the studied unflavored and flavored olive oils. On the other hand, an increasing trend was found by Malheiro et al. (2009) for unflavored Portuguese olive oils and by Sevim et al. (2018) for Turkish olive oils, subjected to similar microwave heating time-periods (1-15 min and 3-15 min, respectively). Oppositely, Cerretani et al. (2009) reported the decreasing of the PV of Italian olive oils with the increasing microwave heating time (from 1.5 to $15 \mathrm{~min}$ ), similarly to the findings of Yan et al. (2020). Finally, higher extinction coefficients $\left(K_{232}\right.$ and $\left.K_{268}\right)$ were observed for higher flavoring levels as well as for greater heating times, pointing out a possible pro-oxidant behavior enhanced by the thermal degradation due to the rise of both factors, with a rise of primary and secondary oxidation products. In the literature, contradictory effects have been reported regarding the oils' flavoring effect, being described both increasing (Baiano et al., 2009; Caponio et al., 2016; Sacchi et al., 2017) and decreasing (Bobiano et al., 2019; Tarchoune et al., 2019) trends of the evaluated quality parameters with the increase of the flavoring levels. It should be noticed that a similar increasing tendency of the extinction coefficients during the microwave heating 


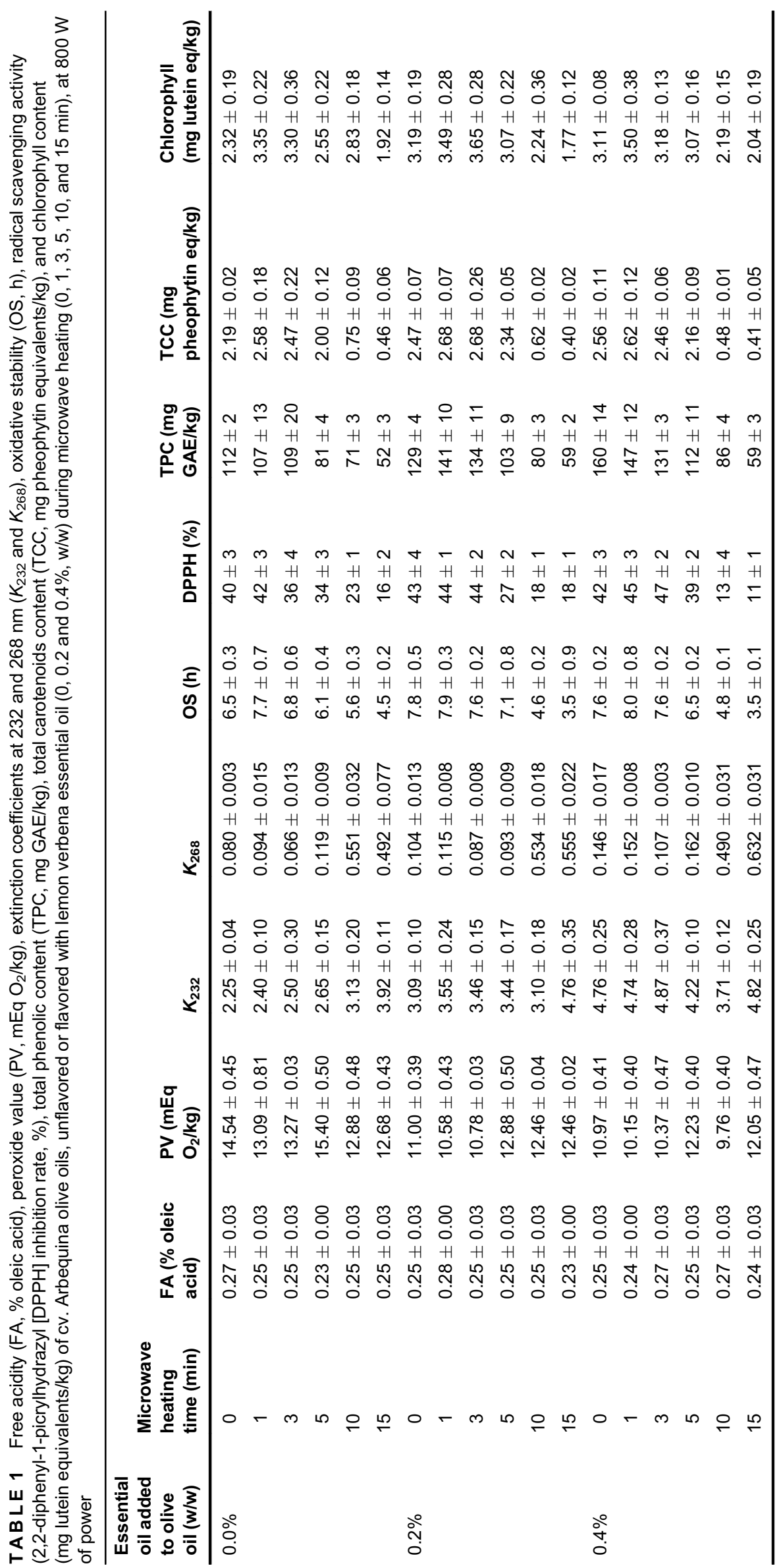




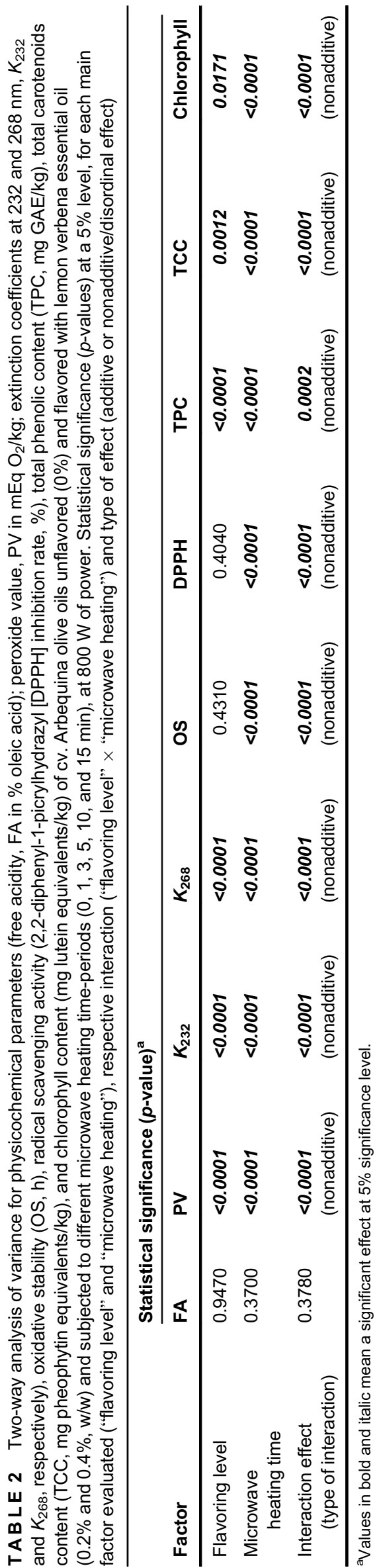

has been previously reported in the literature for different unflavored olive oils (Kishimoto, 2019; Malheiro et al., 2009; Sevim et al., 2018).

Concerning the OS, DPPH, TPC, TCC, and chlorophyll content, from Table 1, it could be inferred that, for unheated samples (0 min), except for TPC and TCC, the flavoring level did not promote a clear increase of those parameters on flavored $(0.2 \%$ and $0.4 \% \mathrm{EO})$ compared to the unflavored oils ( $0 \%$ EO). Flavoring resulted in a linear increase of the TPC (112-160 mg GAE $/ \mathrm{kg}$ oil, $R$-Pearson $=+0.9870$ ) and of the TCC (2.19-2.56 mg lutein equivalents $/ \mathrm{kg}$ oil, $R$-Pearson $=+0.9611)$, but not so evident for chlorophyll content (2.32-3.19 mg pheophytin equivalents $/ \mathrm{kg}$ oil, $R$-Pearson $=+0.8238$ ). Previously, Cherif et al. (2021) reported a decrease of the OS and an increase of both TPC and DPPH with the increase of the lemon verbena EO flavoring level in cv. Arbequina oils. In the literature, both increasing and decreasing trends have been reported, depending on several factors such as the type and level of flavoring agent, the type and quality of the olive oil, and the storage conditions (Baiano et al., 2009; Bobiano et al., 2019; Farhoosh \& HoseiniYazdi, 2014; Khemakhem et al., 2015; Taoudiat et al., 2018; Tarchoune et al., 2019; Veloso et al., 2020). Concerning the microwave heating timeperiod, it had an obvious negative impact on the OS, DPPH, TPC, TCC, and chlorophyll content, leading to a marked decrease of their values, mainly for heating times between 5 and 15 min. Moreover, in general, the EO addition did not have a clear protective effect against the thermal degradation of the oils' quality, and similar levels were found in both unflavored and flavored oils after 10-15 min of microwave heating. The OS decrease for higher heating time-periods was expected since it would correspond to oils heated at higher temperatures, being known that the OS of olive oils decrease when the temperature rises, for both unflavored and flavored olive oils (Cherif et al., 2021; Farhoosh \& Hoseini-Yazdi, 2014; Heidarpour \& Farhoosh, 2018; Veloso et al., 2020). Also, Prata et al. (2018) reported a drastic reduction of the TPC of unflavored Portuguese commercial olive oils during microwave heating (1.5-10 $\mathrm{min}$, corresponding to $\left.72-205^{\circ} \mathrm{C}\right)$ compared to unheated olive oils $\left(20^{\circ} \mathrm{C}\right)$. Similar findings were reported by Cerretani et al. (2009) and Kishimoto (2019). Oueslati et al. (2020) also verified the oxidative and hydrolytic degradation of the different phenolic subclasses due to microwave heating (2-15 min, corresponding to $139-268^{\circ} \mathrm{C}$ ) of $\mathrm{cv}$. Chétoui virgin olive oils, compared to that of unheated oils, as well as a slight decrease of the DPPH inhibition rate.

Lastly, the impact of the flavoring and microwave heating on the physicochemical and antioxidant characteristics of the studied cv. Arbequina oils is evidenced by their unsupervised PCA satisfactory differentiation (Figure 1). The PCA biplot clearly pointed 


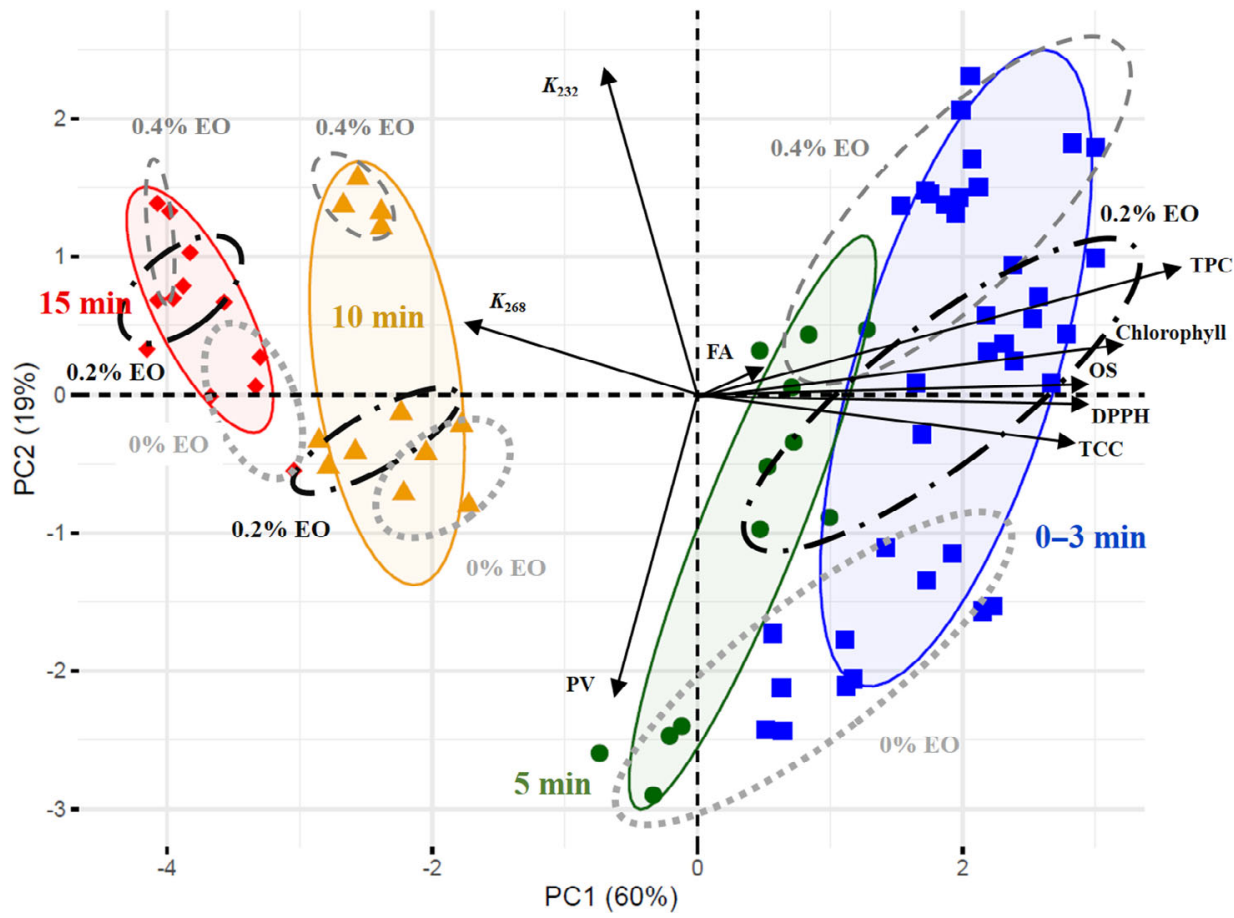

FIGURE 1 Principal component analysis biplot based on the cv. Arbequina olive oils' quality data, composition, and antioxidant activity (free acidity, \% oleic acid; peroxide value, $\mathrm{mEq} \mathrm{O} / 2 / \mathrm{kg} ; K_{232} ; K_{268}$; oxidative stability, h; 2,2-diphenyl1-picrylhydrazyl, \%; total phenols content, $\mathrm{mg} \mathrm{GAE} / \mathrm{kg}$; total carotenoids content, mg pheophytin equivalents/ $\mathrm{kg}$; and, chlorophyll content, mg lutein equivalents $/ \mathrm{kg}$ ): Unsupervised classification according to the flavoring level with lemon verbena essential oils (EO) $(. . . . . .0 \%$ EO; — - : 0.2\% EO; and, - . - : 0.4\% EO) and microwave heating time ( $\mathbf{\square}: 0-3 \mathrm{~min}$; $\mathbf{\bullet} 5 \mathrm{~min}$; $\mathbf{\Delta}$ : $10 \mathrm{~min}$; and, $\bullet: 15 \mathrm{~min}$ )

out that the microwave heating time had a greater impact on the changes of the parameters evaluated compared to the oils' flavoring, allowing a clear unsupervised grouping of the oil samples according to the time-periods (first principal component function, i.e., $x$-axis, with the higher heating time-periods on the negative region and the lower heating time-periods on the positive region). Specifically, oils heated for 0-3 min and 5 min could be clearly split from those heated during 10 or $15 \mathrm{~min}$, for which the quality degradation was more drastic (higher PV, $K_{232}$ and $K_{268}$ and quite lower TPC, OS, DPPH, TCC, and chlorophyll content). On the other hand, the flavoring level grouping split is mainly linked to the second principal component function ( $y$-axis) being the lower flavoring level ( $0 \% \mathrm{EO})$ located in the negative part of the axis (higher PV values and lower extinction coefficients) and the higher level $(0.4 \%)$ placed on the positive region (higher extinction coefficients and lower PV), independently of the heating time-period.

\section{Kinetic modeling of TPC, TCC, and chlorophyll thermal degradation on unflavored and flavored cv. Arbequina oils during microwave heating}

Chemical degradation reactions occurring in foods during processing or storage can be modeled using kinetic models of different reaction orders. Zero-, first-, and second-order models have been applied to describe the thermal degradation of bioactive compounds (e.g., phytosterols, phenolic compounds, carotenoids, vitamin $\mathrm{C}$, chlorophyll, vitamin $\mathrm{C}$ ) in different food matrices (e.g., apple peel by-products, beans, Brussels sprouts, fruit juices, betel extracts, plum extracts, dried flowers, and floral bio-residues of saffron, edible an nonedible vegetable oils, sea buckthorn) during storage or processing (e.g., different types of cooking processes) (Ali et al., 2018; Aparicio-Ruiz et al., 2011; Henríquez et al., 2014; Igoumenidis et al., 2011; Mba et al., 2019; Moratalla-López et al., 2019; NakilciogluTaş \& Otleş, 2017; Sapei \& Hwa, 2014; Turturică et al., 2016; Ursache et al., 2017; Van Bree et al., 2012). A brief survey clearly pointed out that the first-order kinetic model is the most used one to describe the thermal impact at the bioactive composition level of the food matrices. In which concerns the olive oil, the number of studies is limited. Igoumenidis et al. (2011) studied the degradation of $\beta$-sitosterol and total phytosterols in virgin olive oils during repeated deep and pan-frying of prefried potatoes, reporting that the first-order model was superior compared to the zero-order and second-order models. Also, AparicioRuiz et al. (2011) proposed a first-order kinetic mechanism to model the thermal degradation of lutein, $\beta$-carotene, and $\beta$-cryptoxanthin in virgin olive oils subjected to different heat treatments (from $42 \mathrm{~h} / 120^{\circ} \mathrm{C}$ to $\left.744 \mathrm{~h} / 60^{\circ} \mathrm{C}\right)$.

In this context, the thermal degradation of TPC, TCC, and chlorophyll occurred in each type of olive oil studied (unflavored and flavored oils) due to the microwave heating process at a constant microwave power of $800 \mathrm{~W}$ (from 1 to $15 \mathrm{~min}$, which would roughly correspond to a temperature range varying from approximately $41-235^{\circ} \mathrm{C}$ ) was further evaluated from a kinetic 
T A B L E 3 Rate constants ( $k \pm$ standard error [SE]), correlation coefficients $(R)$ and half-life values $\left(t_{1 / 2}\right)$ estimated assuming a second-order kinetic mechanism for the thermal degradation due to microwave heating (0-15 min) at $800 \mathrm{~W}$, for total phenols (TPC), total carotenoids (TCC), and chlorophyll contents, of cv. Arbequina olive oils without ( $0 \%$ essential oil [EO]) or with the addition $(0.2 \%$ and $0.4 \%)$ of lemon verbena EO

\begin{tabular}{|c|c|c|c|}
\hline \multirow[t]{2}{*}{ EO added to olive oil (w/w) } & \multicolumn{3}{|l|}{ TPC } \\
\hline & $\begin{array}{l}\text { Second-order rate reaction constant }(k \pm \mathrm{SE} ; \mathrm{kg} \\
\left.\qquad \mathrm{min}^{-1} \mathrm{mg}^{-1} \mathrm{GAE}\right)^{\mathrm{a}}\end{array}$ & Correlation coefficient $(R)$ & Half-life $\left(\mathrm{t}_{1 / 2} ; \min \right)^{\mathrm{b}}$ \\
\hline $0 \%$ EO & $(70 \pm 9) \times 10^{-5}$ & 0.9760 & 12.2 \\
\hline $0.2 \% \mathrm{EO}$ & $(72 \pm 5) \times 10^{-5}$ & 0.9920 & 10.8 \\
\hline $0.4 \%$ EO & $(71 \pm 7) \times 10^{-5}$ & 0.9848 & 8.8 \\
\hline EO added to olive oil (w/w) & TCC & & \\
\hline $0 \% \mathrm{EO}$ & $0.14 \pm 0.02$ & 0.9775 & 3.4 \\
\hline $0.2 \% \mathrm{EO}$ & $0.16 \pm 0.02$ & 0.9731 & 2.5 \\
\hline $0.4 \%$ EO & $0.17 \pm 0.03$ & 0.9541 & 2.3 \\
\hline EO added to olive oil (w/w) & Chlorophyll content & & \\
\hline $0.2 \% \mathrm{EO}$ & $0.022 \pm 0.002$ & 0.9845 & 14.5 \\
\hline $0.4 \%$ EO & $0.016 \pm 0.002$ & 0.9769 & 20.2 \\
\hline
\end{tabular}

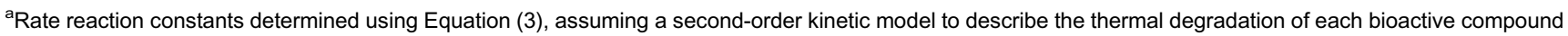
(content decrease) in the studied olive oils, when subjected to increasing microwave heating time-periods (0-15 min).

${ }^{b}$ Half-life values calculated using Equation (10), assuming a second-order kinetic model to describe the thermal degradation of each bioactive compound (content decrease) in the studied olive oils, when subjected to increasing microwave heating time-periods (0-15 min).

point of view. Zero-order, first-order, and second-order kinetic models were considered. The results allowed verifying that, globally, the second-order model was the one that better fitted the thermal degradation process of the referred three parameters for all oils studied $(0.8784 \leq R$-Pearson $\leq 0.9926)$. Table 3 shows the second-order rate constants ( \pm SE), calculated as the slope of the linear regression of the inverse of the concentration versus the heating time (according to Equation (3), obtained after the linearization of kinetic model), the correlation coefficient, and the estimated half-life (determined using Equation (10)), for each compound and type of olive oil studied. The estimated second-order reaction rates for TPC $(0.00070-0.00072$ $\mathrm{kg}$ oil $\left.\mathrm{min}^{-1} \mathrm{mg}^{-1} \mathrm{GAE}\right)$ and for TCC $(0.14-0.17 \mathrm{~kg}$ oil $\mathrm{min}^{-1} \mathrm{mg}^{-1}$ lutein equivalents), regarding the thermal degradation of the $\mathrm{cv}$. Arbequina oils during microwave heating, were not influenced by the EO incorporation. In contrast, the level of EO added seemed to influence the degradation rate of chlorophyll $(0.014-0.022 \mathrm{~kg}$ oil $\mathrm{min}^{-1} \mathrm{mg}^{-1}$ pheophytin equivalents), although no direct trend could be established with the flavoring percentage. On the other hand, and as a possible shelf-life inference, it was observed that, for unflavored and flavored oils, the TCC suffered a faster degradation (halflife of 3.4 to $2.3 \mathrm{~min}$, respectively), compared to TPC (half-life from 12.8 to $8.8 \mathrm{~min}$, respectively) and chlorophyll (half-life between 30.8 and 14.5 min, respectively), being this latter the most thermal resistant. Besides, with the exception of chlorophyll, the half-life of TPC and TCC linearly decreased with the rise of added EO level ( $R$-Pearson equal to -0.9999 and -0.9421 , respectively). This finding is of utmost relevance since, although lemon verbena EO was added to the $\mathrm{cv}$. Arbequina olive oil aiming to enhance its resistance toward quality thermal degradation, the oils' flavoring did not have a protective effect against the degradation of these bioactive compounds when subjected to a microwave heating. In fact, on the contrary, this EO promoted the degradation of these bioactive compounds.

\section{CONCLUSIONS}

The study allowed concluding that flavoring $\mathrm{cv}$. Arbequina olive oils with lemon verbena EO had a positive impact on the levels of minor bioactive compounds, increasing the total phenols and carotenoids contents, although this did not have a direct and clear effect on the oils' OS on the radical scavenging activity. On the other hand, the quality of the unflavored and flavored oils was clearly degraded after being subjected to microwave heating time-periods that mimic usual domestic cooking procedures and at a usual power of $800 \mathrm{~W}$. Furthermore, based on the half-life determined based on the second-order rate reaction constants, chlorophyll was the minor constituent most thermally resistant followed by phenols and carotenoids. Indeed, 
the kinetic evaluation pointed out that the olive oils' thermal degradation was not delayed by the EO addition, seeming that the flavoring procedure promoted a faster decrease of total contents of the minor bioactive constituents. In conclusion, from this study emerges the need to perform a preliminary thermalkinetic evaluation when any olive oil flavoring process is envisaged, namely under typical domestic cooking application, to ensure the benefit of the flavoring practice. Finally, it should be remarked that, since olive oil was studied alone, the interactions between the oil and other food ingredients during the microwave heating of a specific meal were not taken into account, which must be addressed in a future work. Indeed, the type and amounts of bioactive compounds present in the other food ingredients may play a key role on the extent and speed of the thermal degradation of the olive oil.

\section{ACKNOWLEDGMENTS}

The authors are grateful to the Foundation for Science and Technology (FCT, Portugal) for financial support by national funds FCT/MCTES to CIMO (UIDB/00690/ 2020), to CEB (UIDB/04469/2020) and to BioTecNorte operation (NORTE-01-0145-FEDER-000004) and Project "GreenHealth-Digital strategies in biological assets to improve well-being and promote green health" (Norte01-0145-FEDER-000042) funded by the European Regional Development Fund under the scope of Norte2020_Programa Operacional Regional do Norte. Nuno Rodrigues thanks the National funding by FCTFoundation for Science and Technology, P.I., through the institutional scientific employment program-contract.

\section{AUTHOR CONTRIBUTION}

Conceptualization: Nuno Rodrigues, José A. Pereira, António M. Peres; Methodology: Nuno Rodrigues, Ana C.A. Veloso; Data analysis and interpretation: Nuno Rodrigues, Ana C.A. Veloso, José A. Pereira, António M. Peres; Investigation: Marwa Cherif; Data Curation: Marwa Cherif; Writing andediting: All authors; Revision and final approval: All authors.

\section{CONFLICT OF INTEREST}

The authors declare that they have no conflict of interest.

\section{ETHICS STATEMENT}

This article does not contain any studies with human participants or animals performed by any of the authors.

\section{ORCID}

José Alberto Pereira (1) https://orcid.org/0000-00022260-0600

António M. Peres (10 https://orcid.org/0000-0001-65959165

\section{REFERENCES}

Aamir M, Boonsupthip W. Effect of microwave drying on quality kinetics of okra. J Food Sci Technol. 2017;54:1239-47. https://doi. org/10.1007/s13197-017-2546-3

Ali A, Chong CH, Mah SH, Abdullah LC, Choong TSY, Chua BL. Impact of storage conditions on the stability of predominant phenolic constituents and antioxidant activity of dried Piper betle extracts. Molecules. 2018;23:84. https://doi.org/10.3390/molecules23020484

Aparicio-Ruiz R, Mínguez-Mosquera MI, Gandul-Rojas B. Thermal degradation kinetics of lutein, $\beta$-carotene and $\beta$-cryptoxanthin in virgin olive oils. J Food Compos Anal. 2011;24:811-20. https:// doi.org/10.1016/j.jfca.2011.04.009

Bahramsoltani R, Rostamiasrabadi $\mathrm{P}$, Shahpiri Z, Marques AM, Rahimi R, Farzaei MH. Aloysia citrodora Paláau (Lemon verbena): a review of phytochemistry and pharmacology. J Ethnopharmacol. 2018;222:34-51. https://doi.org/10.1016/j. jep.2018.04.021

Baiano A, Terracone C, Gambacorta G, La Notte EL. Changes in quality indices, phenolic content and antioxidant activity of flavored olive oils during storage. J Am Oil Chem Soc. 2009;86: 1083-92. https://doi.org/10.1007/s11746-009-1446-8

Bobiano M, Rodrigues N, Madureira M, Dias LG, Veloso ACA, Pereira JA, et al. Unmasking sensory defects of olive oils flavored with basil and oregano using an electronic tonguechemometric tool. J Am Oil Chem Soc. 2019;96:751-60. https:// doi.org/10.1002/aocs.12249

Cadima J, Cerdeira JO, Minhoto M. Computational aspects of algorithms for variable selection in the context of principal components. Comput Stat Data Anal. 2004;47:225-36. https://doi.org/ 10.1016/j.csda.2003.11.001

Caponio F, Durante V, Varva G, Silletti R, Previtali MA, Viggiani I, et al. Effect of infusion of spices into the oil vs. combined malaxation of olive paste and spices on quality of naturally flavoured virgin olive oils. Food Chem. 2016;202:221-8. https://doi.org/10. 1016/j.foodchem.2016.02.005

Cerretani L, Bendini A, Rodriguez-Estrada MT, Vittadini E, Chiavaro E. Microwave heating of different commercial categories of olive oil: part I. Effect on chemical oxidative stability indices and phenolic compounds. Food Chem. 2009;115:1381-8. https://doi.org/10.1016/j.foodchem.2009.01.060

Cherif M, Rodrigues N, Veloso ACA, Zaghdoudi K, Pereira JA, Peres AM. Kinetic-thermodynamic study of the oxidative stability of Arbequina olive oils flavored with lemon verbena essential oil. LWT-Food Sci Technol. 2021;140:110711. https://doi.org/10. 1016/j.Iwt.2020.110711

Chiou A, Kalogeropoulos N. Virgin olive oil as frying oil. Compr Rev Food Sci Food Saf. 2017;16:632-46. https://doi.org/10.1111/ 1541-4337.12268

Combrinck S, Bosman AA, Botha BM, du Plooy W, McCrindle RI, Retief E. Effects of postharvest drying on the essential oil and glandular tric-Chomes of Lippia scaberrima Sond. J Essent Oil Res. 2019;18:80-4. https://doi.org/10.1080/10412905.2006.12067126

Commission Delegated Regulation (EU) 2015/1830. Amending Regulation (EEC) No 2568/91 on the characteristics of olive oil and olive-residue oil and on the relevant methods of analysis. Off $\mathrm{J}$ Eur Union. 2015;L266:9-13.

Dadali G, Ozbek B. Kinetic thermal degradation of vitamin C during microwave drying of okra and spinach. Int J Food Sci Nutr. 2009;60:21-31. https://doi.org/10.1080/09637480701568038

Dadali G, Apar DK, Özbek B. Microwave drying kinetics of okra. Drying Technol. 2007;25:917-24. https://doi.org/10.1080/ 07373930701372254

Demirhan, E, \& Özbek, B. Color change kinetics of microwave-dried basil. Dry Technol. 2009;27:156-166. https://doi.org/10.1080/ 07373930802566101

Demirhan E, Özbek B. Color change kinetics of tea leaves during microwave drying. Int J Food Eng. 2015;11:255-63. https://doi. org/10.1515/ijfe-2014-0276 
Emma MR, Augello G, Di Stefano V, Azzolina A, Giannitrapani L, Montalto $G$, et al. Potential uses of olive oil secoiridoids for the prevention and treatment of cancer: a narrative review of preclinical studies. Int J Mol Sci. 2021;22:1234. https://doi.org/10.3390/ ijms22031234

Farhoosh R, Hoseini-Yazdi S-Z. Evolution of oxidative values during kinetic studies on olive oil oxidation in the Rancimat test. J Am Oil Chem Soc. 2014;91:281-93. https://doi.org/10.1007/s11746013-2368-z

Field A. Discovering statistics using SPSS. 3rd ed. London: Sage Publications Ltd.; 2009.

Heidarpour M, Farhoosh R. A preliminary Rancimat based kinetic approach of detecting olive oil adulteration. LWT-Food Sci Technol. 2018;90:77-82. https://doi.org/10.1016/j.Iwt.2017. 12.015

Henríquez C, Córdova A, Almonacid S, Saavedra J. Kinetic modeling of phenolic compound degradation during drum-drying of apple peel by-products. J Food Eng. 2014;143:146-53. https://doi.org/ 10.1016/j.jfoodeng.2014.06.037

Igoumenidis PE, Konstanta MA, Salta FN, Karathanos VT. Phytosterols in frying oils: evaluation of their absorption in pre-fried potatoes and determination of their destruction kinetics after repeated deep and pan frying. Procedia Food Sci. 2011;1:608-15.

IItter I, Akyıl S, Devseren E, Okut D, Koç M, Kaymak Ertekin F. Microwave and hot air drying of garlic puree: drying kinetics and quality characteristics. Heat Mass Transf. 2018;54:2101-12. https:// doi.org/10.1007/s00231-018-2294-6

Ishkeh SR, Asghari M, Shirzad H, Alirezalu A, Ghasemi G. Lemon verbena (Lippia citrodora) essential oil effects on antioxidant capacity and phytochemical content of raspberry (Rubus ulmifolius subsp. sanctus). Sci Hortic. 2019;248:297-304. https://doi.org/10.1016/j.scienta.2018.12.040

Jaiswal AK, Abu-Ghannam N. Degradation kinetic modelling of color, texture, polyphenols and antioxidant capacity of York cabbage after microwave processing. Food Res Int. 2013;53:125-33. https://doi.org/10.1016/j.foodres.2013.04.007

Javidipour I, Erinç H, Baştürk A, Tekin A. Oxidative changes in hazelnut, olive, soybean, and sunflower oils during microwave heating. Int J Food Prop. 2017;20:1582-92. https://doi.org/10. 1080/10942912.2016.1214963

Jiménez $P$, García $P$, Bustamante A, Barriga A, Robert P. Thermal stability of oils added with avocado (Persea americana cv. Hass) or olive (Olea europaea cv. Arbequina) leaf extracts during the French potatoes frying. Food Chem. 2017;221:123-9. https://doi.org/10.1016/j.foodchem.2016.10.051

Khemakhem I, Yaiche C, Ayadi MA, Bouaziz M. Impact of aromatization by Citrus limetta and Citrus sinensis peels on olive oil quality, chemical composition and heat stability. J Am Oil Chem Soc. 2015;92:701-8. https://doi.org/10.1007/s11746-015-2636-1

Kishimoto $\mathrm{N}$. Microwave heating induces oxidative degradation of extra virgin olive oil. Food Sci Technol Res. 2019;25:75-9. https://doi.org/10.3136/fstr.25.75

Kumar V, Kalpana Devi M, Lal Shrivastava S. Color change kinetics of green bell pepper dried under vacuum-assisted microwave system. J Agric Sci Technol. 2019;21:601-14.

Malheiro R, Oliveira I, Vilas-Boas M, Falcão S, Bento A, Pereira JA. Effect of microwave heating with different exposure times on physical and chemical parameters of olive oil. Food Chem Toxicol. 2009;47:92-7. https://doi.org/10.1016/j.fct.2008.10.014

Marszałek K, Skapska S, Woźniak Ł, Sokołowska B. Application of supercritical carbon dioxide for the preservation of strawberry juice: microbial and physicochemical quality, enzymatic activity and the degradation kinetics of anthocyanins during storage. Innov Food Sci Emerg Technol. 2015;32:101-9. https://doi.org/ 10.1016/j.ifset.2015.10.005

Martins CA, Andrade GC, Oliveira MFBD, Rauber F, Castro IRRD, Couto MT, et al. "Healthy", "usual" and "convenience" cooking practices patterns: how do they influence children's food consumption? Appetite. 2021;158:105018. https://doi.org/10. 1016/j.appet.2020.105018

Mba OI, Kwofie EM, Ngadi M. Kinetic modelling of polyphenol degradation during common beans soaking and cooking. Heliyon. 2019;5:e01613. https://doi.org/10.1016/j.heliyon.2019.e01613

Moratalla-López N, Lorenzo C, Chaouqi S, Sánchez AM, Alonso GL. Kinetics of polyphenol content of dry flowers and floral bioresidues of saffron at different temperatures and relative humidity conditions. Food Chem. 2019;290:87-94. https://doi.org/10. 1016/j.foodchem.2019.03.129

Nakilcioglu-Taş E, Otleş S. Degradation kinetics of bioactive compounds and antioxidant capacity of Brussels sprouts during microwave processing. Int J Food Prop. 2017;20:S2798-809. https://doi.org/10.1080/10942912.2017.1375944

Oueslati I, Taamalli A, Loubiri A, Arráez-Román D, SeguraCarretero A, Zarrouk M. Assessment of conventional and microwave heating effects on the variation of the bioactive compounds of Chétoui VOO using HPLC-DAD-ESI-TOF-MS. Arabian J Chem. 2020;13:954-65. https://doi.org/10.1016/j. arabjc.2017.08.011

Pizarro ML, Becerra M, Sayago A, Beltrán M, Beltrán R. Comparison of different extraction methods to determine phenolic compounds in virgin olive oil. Food Anal Methods. 2013;6:123-32. https://doi.org/10.1007/s12161-012-9420-8

Pocovi-Gerardino G, Correa-Rodríguez M, Callejas-Rubio J-L, Ríos-Fernández R, Martín-Amada M, Cruz-Caparros M-G, et al. Beneficial effect of Mediterranean diet on disease activity and cardiovascular risk in systemic lupus erythematosus patients: a cross-sectional study. Rheumatology. 2021;60:160-9. https:// doi.org/10.1093/rheumatology/keaa210

Prata R, Pereira JA, Rodrigues N, Dias LG, Veloso ACA, Casal $\mathrm{S}$, et al. Olive oil total phenolic contents and sensory sensations trends during oven and microwave heating processes and their discrimination using an electronic tongue. J Food Qual. 2018;2018:7826428. https://doi.org/10.1155/ $2018 / 7826428$

Minguez-Mosquera MI, Rejano-Navarro L, Gandul-Rojas B, Sanchez Gomez AH, Garrido-Fernandez J. Color-pigment correlation in virgin olive oil. J Am Oil Chem Soc. 1991;68:332-6. https://doi. org/10.1007/BF02657688

Rocha C, Coelho M, Lima RC, Campos FM, Pintado M, Cunha LM. Increasing phenolic and aromatic compounds extraction and maximizing liking of lemon verbena (Aloysia triphylla) infusions through the optimization of steeping temperature and time. Food Sci Technol Int. 2019;25:701-10. https://doi.org/10.1177/ 1082013219860352

Sacchi R, Medaglia DD, Paduano A, Caporaso N, Genovese A. Characterisation of lemon-flavoured olive oils. LWT-Food Sci Technol. 2017;79:326-32. https://doi.org/10.1016/j.Iwt.2017. 01.025

Sapei A, Hwa L. Study on the kinetics of vitamin C degradation in fresh strawberry juices. Procedia Chem. 2014;9:62-8. https:// doi.org/10.1016/j.proche.2014.05.008

Sevim D, Köseoğlu O, Casale M, Altunoğlu Y, Kadiroğlu P. Influence of microwave heating on quality parameters and chemical characteristics of Turkish olive oils. Riv Ital Sostanze Grasse. 2018; 95:229-37.

Taoudiat A, Djenane D, Ferhat Z, Spigno G, Aldjia T, Djamel D, et al. The effect of Laurus nobilis L. essential oil and different packaging systems on the photo-oxidative stability of Chemlal extravirgin olive oil. J Food Sci Technol. 2018;55:4212-22. https:// doi.org/10.1007/s13197-018-3357-x

Tarchoune I, Sgherri C, Eddouzi J, Zinnai A, Quartacci MF, Zarrouk M. Olive leaf addition increases olive oil nutraceutical properties. Molecules. 2019;24:545. https://doi.org/10.3390/ molecules24030545

Turturică M, Stănciuc N, Bahrim G, Râpeanu G. Effect of thermal treatment on phenolic compounds from plum (Prunus 
domestica) extracts - a kinetic study. J Food Eng. 2016;171 200-7. https://doi.org/10.1016/j.jfoodeng.2015.10.024

Ursache F-M, Ghinea IO, Turturică M, Aprodu I, Râpeanu G, Stănciuc N. Phytochemicals content and antioxidant properties of sea buckthorn (Hippophae rhamnoides L.) as affected by heat treatment - quantitative spectroscopic and kinetic approaches. Food Chem. 2017;233:442-9. https://doi.org/10. 1016/j.foodchem.2017.04.107

Van Bree I, Baetens JM, Samapundo S, Devlieghere F, Laleman R, Vandekinderen I, et al. Modelling the degradation kinetics of vitamin $C$ in fruit juice in relation to the initial headspace oxygen concentration. Food Chem. 2012;134:207-14. https://doi.org/10. 1016/j.foodchem.2012.02.096

Veloso ACA, Rodrigues N, Ouarouer Y, Zaghdoudi K, Pereira JA, Peres AM. A kinetic-thermodynamic study of the effect of the cultivar/total phenols on the oxidative stability of olive oils. J Am Oil Chem Soc. 2020;97:625-36. https://doi.org/10.1002/aocs.12351

Venables WN, Ripley BD. Modern applied statistics with S (statistics and computing). 4th ed. New York, NY: Springer; 2002.
Yan J, Zhu L, Yu W, Yang H, Liu X, Gao C, et al. Impact on edible oil quality and fatty acid composition by microwave heating. J Chin Cereals Oils Assoc. 2020;35:110-5.

Yarahmadi N, Hojjatoleslamy M, Sedaghat Boroujeni L. Different drying methods of Pistacia atlantica seeds: impact on drying kinetics and selected quality properties. Food Sci Nutr. 2020;8:322533. https://doi.org/10.1002/fsn3.1582

How to cite this article: Cherif $\mathrm{M}$, Rodrigues $\mathrm{N}$, Veloso ACA, Pereira JA, Peres AM. Kinetic study of the microwave-induced thermal degradation of cv. Arbequina olive oils flavored with lemon verbena essential oil. J Am Oil Chem Soc. 2021; 98:1021-32. https://doi.org/10.1002/aocs.12519 